\title{
A New MEMS-Based System for Ultra-High-Resolution Imaging at Elevated Temperatures
}

\author{
LAWRENCE F. ALLARD, ${ }^{1 *}$ WILBUR C. BIGELOW, ${ }^{2}$ MIGUEL JOSE-YACAMAN,${ }^{3}$ DAVID P. NACKASHI, ${ }^{4}$ \\ JOHN DAMIANO ${ }^{4}$ AND STEPHEN E. MICK ${ }^{4}$ \\ ${ }^{1}$ Materials Science and Technology Division, Oak Ridge National Laboratory, Oak Ridge, Tennessee 37831 \\ ${ }^{2}$ Department of Materials Science and Engineering, University of Michigan, Ann Arbor, Michigan 48109 \\ ${ }^{3}$ Department of Chemical Engineering, The University of Texas at Austin, Austin, Texas 78712 \\ ${ }^{4}$ Protochips Inc., 840 Main Campus Drive, Suite 3500, Raleigh, North Carolina 27606
}

\begin{abstract}
KEY WORDS MEMS device; electron microscopy; aberration-corrected; STEM; elevated temperature; in situ
\end{abstract}

\begin{abstract}
In recent years, an increasing number of laboratories have been applying in situ heating (and ultimately, gas reaction) techniques in electron microscopy studies of catalysts and other nanophase materials. With the advent of aberration-corrected electron microscopes that provide sub-Ångström image resolution, it is of great interest to study the behavior of materials at elevated temperatures while maintaining the resolution capabilities of the microscope. In collaboration with Protochips Inc., our laboratory is developing an advanced capability for in situ heating experiments that overcomes a number of performance problems with standard heating stage technologies. The new heater device allows, for example, temperature cycling from room temperature to greater than $1000^{\circ} \mathrm{C}$ in $1 \mathrm{~ms}$ (a heating rate of 1 million Centigrade degrees per second) and cooling at nearly the same rate. It also exhibits a return to stable operation (drift controlled by the microscope stage, not the heater) in a few seconds after large temperature excursions. With Protochips technology, we were able to demonstrate single atom imaging and the behavior of nanocrystals at high temperatures, using high-angle annular dark-field imaging in an aberration-corrected (S)TEM. The new capability has direct applicability for remote operation and (ultimately) for gas reaction experiments using a specially designed environmental cell. Microsc. Res. Tech. 72:208215, 2009. @ 2009 Wiley-Liss, Inc.
\end{abstract}

\section{INTRODUCTION}

In situ electron microscopy studies of the behavior of materials at elevated temperatures, and often under controlled gaseous environments, have been conducted since the early days of electron microscopy (Baker, 1979; Braski, 1969; Heinemann et al., 1975; Packan and Braski, 1970). Specimens are typically mounted on suitable TEM grids, and placed into specimen holders that contain the heating element, or that fit into heating elements that are permanently mounted inside the objective lens pole piece of the microscope (Boyes and Gai, 1997; Gai, 1999, 2002; Sharma, 2001; Sharma and Weiss, 1998). In both cases, the entire specimen grid and parts of the surrounding holder are heated during the experiment. The heated volume, compared with the specimen region that might be involved in the imaging experiment, is very large in these geometries. An advantage of having a (relatively) large heated region is that the temperature of the sample area under observation is likely to be uniform, and able to be calibrated using thermocouples to give a measure of the temperature experienced by the specimen (not considering, of course, the energy input and heating effect of the electron beam during observations, as well as radiative cooling effects related to sample and holder morphology). A disadvantage, however, is that the large volume that must be heated does not provide the capability for rapid heating and cooling, and therefore does not allow accurate control of the heating process. A second disadvantage of standard heating holders is that image drift at highest magnifications because of thermal effects of the stage/heater makes imaging at the ultimate levels of the microscope problematical. This is particularly true for heating experiments in the latest generation of aberration-corrected electron microscopes, especially for those having correctors on the illuminating lens side to permit sub-Angström images to be recorded using high-angle annular darkfield techniques in scanning transmission mode. Recently developed heater and reaction holders by Kamino et al. and Saka et al. (2005a,b, 2006; 2008) use a thin helical heater coil supporting a thin conductive film (e.g., carbon) on which powders and nanoparticles can be supported. The support film is heated directly

\footnotetext{
*Correspondence to: Lawrence F. Allard, Materials Science and Technology Division, Oak Ridge National Laboratory, 1 Bethel Valley Road, Oak Ridge, Tennessee 37831-6064, USA. E-mail: allardlfjr@ornl.gov

Received 11 April 2008; accepted in revised form 1 October 2008

Contract grant sponsor: Protochips Inc. (Work-for-Others Program); Contract grant number: IAN \# 14B569801; Contract grant sponsor: U.S. Department of Energy; Contract grant number: DE-AC05-00OR22725; Contract grant sponsor: SBIR: Contract grant number: DE-FG02-05ER84252; Contract grant sponsors: SBT , User Program, User Program, Ast. Sec. for Enact grant sponsors: Rene Renewable Energy, Office of Vehicle Technologies, US Department of Energy, Welch Foundation, NSF Materials Division.

DOI 10.1002/jemt.20673

Published online 22 January 2009 in Wiley InterScience (www.interscience. wiley.com).
} 


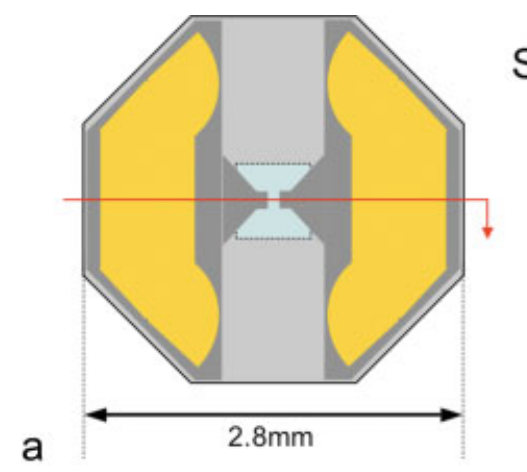

\section{Schematic of "baseline" Aduro device}

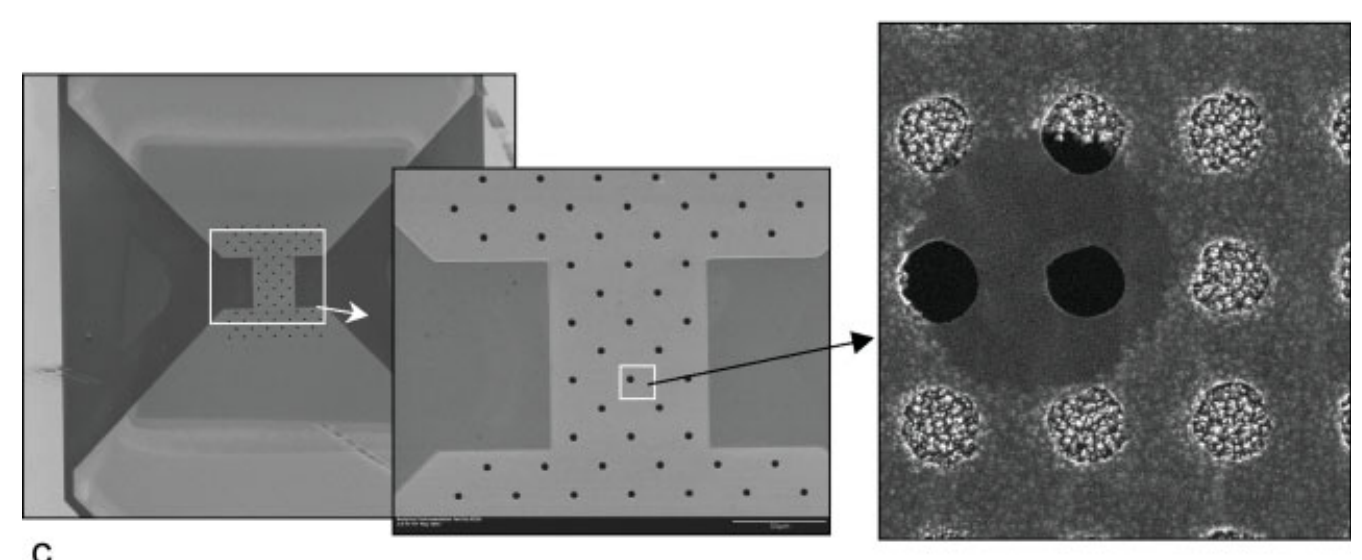

C

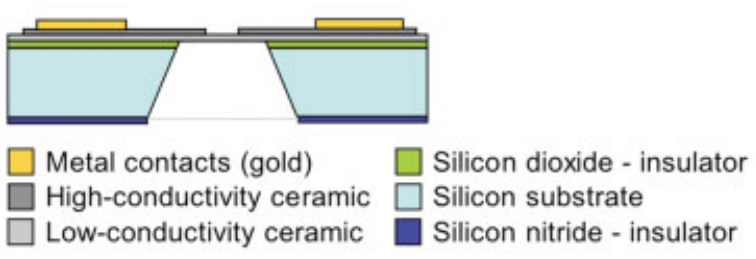

b

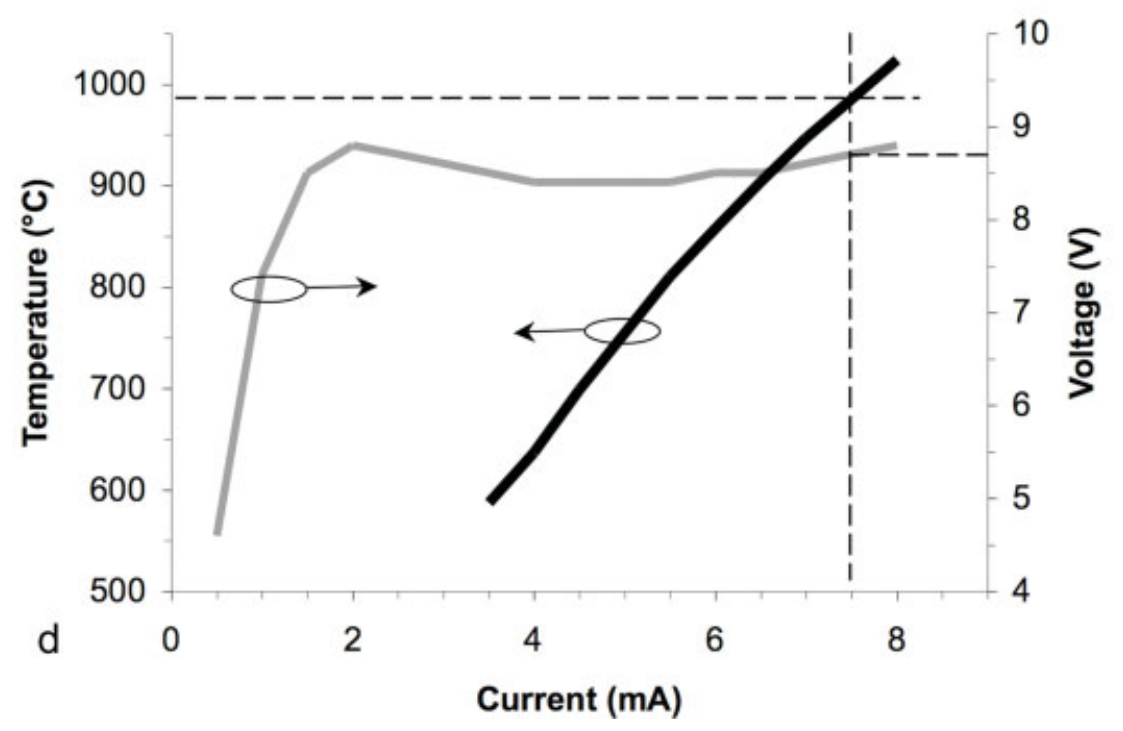

Fig. 1. a: Top view schematic of "baseline" Protochips heater chip. b: Cross-section view of chip, showing composition of the various elements. c: Backscattered electron image of the central region of the chip. The inset shows the pattern of holes in the low-conductivity ceramic membrane. A higher magnification secondary electron image

by current through the coil, subsequently heating the sample material. The low mass of the coil permits relatively rapid heating rates, but there is still a significant time associated with sample drift. For example, according to Figure 1b in (Saka et al., 2008), a drift rate of 0.1 $\mathrm{nm} / \mathrm{s}$ (i.e., $60 \AA / \mathrm{min}$ ) is experienced after 15 min heating time. This performance has been shown to allow shows the carbon support film overlaying a single hole in the ceramic membrane. The holey film supports e.g., catalyst powder samples. $d$ Current and voltage versus temperature plots, for a particular MEMS heater device. At $1000^{\circ} \mathrm{C}$, a power of $0.67 \mathrm{~W}$ is required by this device.

lattice imaging at high temperatures $\left(\sim 1500^{\circ} \mathrm{C}\right)$, butperformance has not been demonstrated to date at sub-Ångström resolution. Our laboratory has recently undertaken a project with Protochips Inc. (Raleigh, NC), to develop a new capability for in situ heating experiments that provides sub-Angström resolution with very rapid specimen heating and cooling by over- 

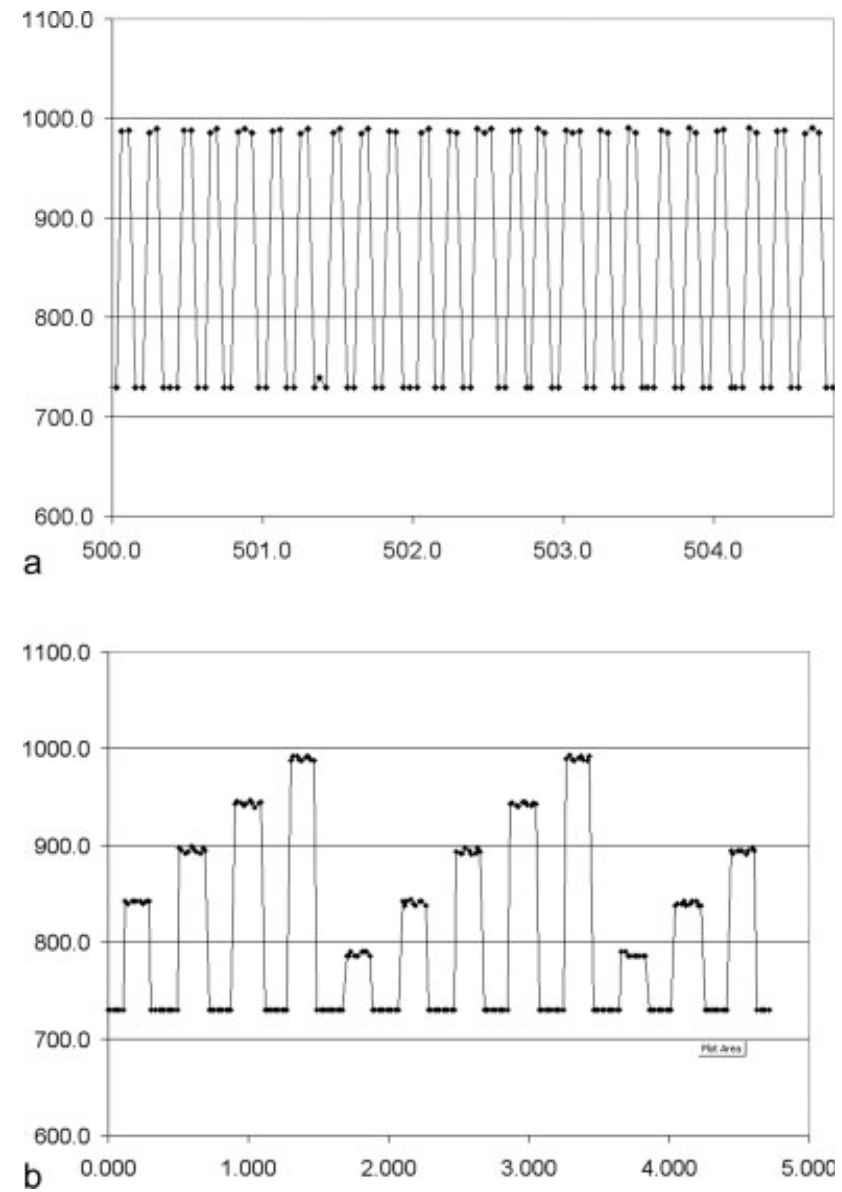

Fig. 2. a: Example of thermal cycling experiment, where the ceramic membrane was cycled between $730^{\circ} \mathrm{C}$ and $990^{\circ} \mathrm{C}$, at the rate of 5 cycles/s. b: Similar thermal cycling experiment, showing step response of membrane from $730^{\circ} \mathrm{C}$ to $990^{\circ} \mathrm{C}$.

coming a number of performance problems with standard heating stage technologies.

\section{MATERIALS AND METHODS}

Protochips provides a heating element that is based upon their patent-pending Aduro ${ }^{\mathrm{TM}}$ technology, a novel semiconductor MEMS technology. The system is composed of a disposable MEMS device that serves both as the heating element and the specimen support grid, a TEM holder with electrical feedthroughs and an external current source. The MEMS devices are microfabricated by Protochips using standard semiconductor processes and bulk micromachining steps. The key component of the MEMS devices is a 150-nm thick, $500-\mu \mathrm{m}$ square, freestanding membrane made from a conductive ceramic that is suspended on a $3-\mathrm{mm} \mathrm{Si}$ chip (Figs. 1a and 1b). This membrane is unique in that it not only supports the sample but also provides the heating surface, minimizing ambiguity by placing the sample directly in contact with the heat source. The ceramic membrane is patterned with a series of 3micron holes, which can be subsequently overlaid with a holey carbon film (Fig. 1c). Current is forced through the membrane using an external constant current sup-

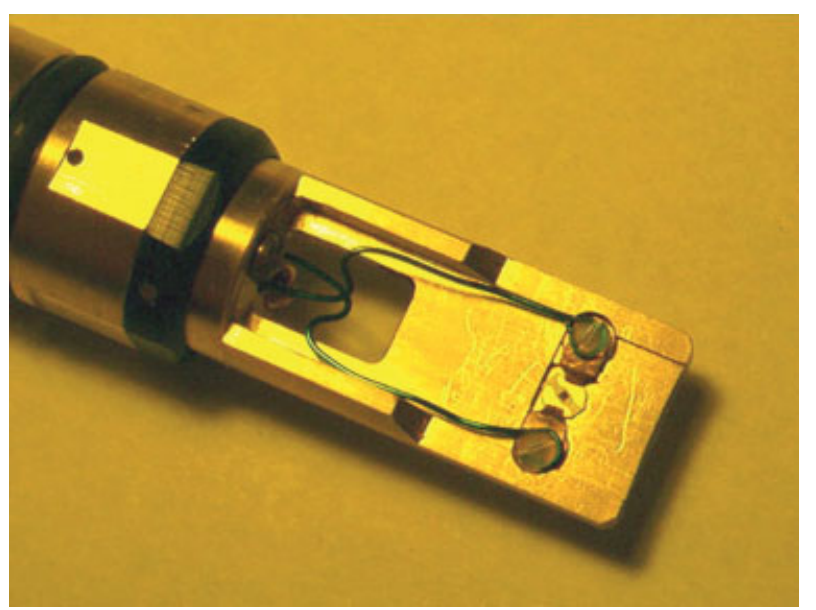

Fig. 3. Tip of prototype specimen holder for JEOL 2200FS electron microscope, showing heater chip clamped into place, with electrical leads connected.

ply (Keithley 2611), and through Joule heating, the desired temperature is achieved as a function of current. Heat distribution across the membrane surface is determined by the device electrode and membrane design. Each chip is calibrated separately in vacuum using a high resolution thermal imaging pyrometer with a microscope lens (Mikron M9104), and a table of current versus temperature up to $1200^{\circ} \mathrm{C}$ is provided. Figure 1d shows characteristic current and voltage behavior versus temperature, for a particular electrode configuration. Because current is forced through the membrane, the measured voltage is simply $\mathrm{I} \times \mathrm{R}$. For low current values, the voltage rises with current, and begins to roll off as the membrane heats up. It plateaus, and then drops gradually as the resistance of the membrane drops quickly ( $\mathrm{R}$ drops faster than $\mathrm{I}$ is rising). In the example of Figure $1 \mathrm{~d}$, a temperature of $1000^{\circ} \mathrm{C}$ is obtained at a current of $7.6 \mathrm{~mA}$ and a voltage of $8.8 \mathrm{~V}$, giving a power of $0.067 \mathrm{~W}$. We have found that power required to heat membranes to a temperature of $1200^{\circ} \mathrm{C}$ typically varies from $0.05-0.30 \mathrm{~W}$, dependent upon electrode configuration. Rates of up to $10^{6 \circ} \mathrm{C} / \mathrm{s}$ for heating (and cooling) are possible because of the very low thermal mass of the membrane. This heating/cooling rate allows the membrane area to be cycled from RT to $>1000^{\circ} \mathrm{C}$ in $1 \mathrm{~ms}$, with virtually instantaneous temperature stabilization. Typical thermal cycling experiments are shown in Figure 2. The plot shown in Figure 2a illustrates cyclic heating between $730^{\circ} \mathrm{C}$ and $990^{\circ} \mathrm{C}$, at a rate of 5 times per second. Figure $2 \mathrm{~b}$ shows a staircase stepping experiment; both experiments utilize the computer control capability of the power supply.

For observations in the electron microscope, the chip is retained in a prototype specimen holder (Fig. 3) with electrical leads provided to clips isolated by nylon screws from the body of the holder, which contact electrode pads on the chip. Samples such as catalyst powders are dispersed over the carbon film on the ceramic heater membrane, either by dry dipping or by depositing a droplet of suspended particles. Prior to loading any conductive sample material, the resistance of the 


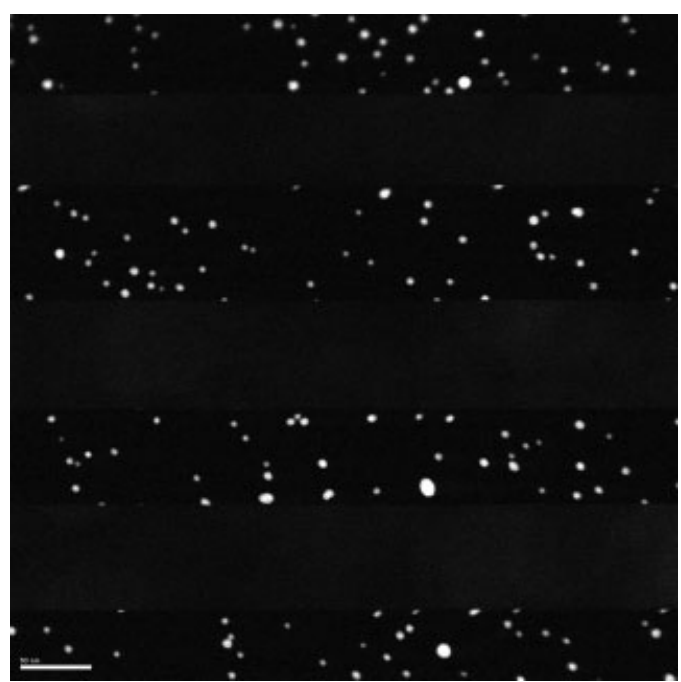

Fig. 4. Heater On-Off experiment, illustrating the rapid return to the original Z-heightposition after cycling from $700^{\circ} \mathrm{C}$ to RT. Darkfield image of heavy metal nanoparticles shows the stability of the focus after a $1.7 \mu \mathrm{m}$ deflection, with the return to the original focus occurring within a single $64 \mathrm{~ms}$ scan line.

heater membrane is measured using a standard Fluke meter. After the sample is deposited on the chip, the resistance is remeasured to assure the electrodes are not short-circuited. Finally, the resistance of the system is confirmed from one lead to the other, after the heater chip is installed in the sample holder, again to assure the chip is ready for a heating experiment.

All images shown in this article were recorded using a JEOL 2200FS-AC STEM-TEM instrument, with a CEOS GmbH (Heidelberg, Germany) aberration corrector fitted on the illumination lens system. At standard settings of the instrument's Schottky emitter, a probe current of $23 \mathrm{pA}$ is obtained with an illumination aperture subtending $26.5 \mathrm{mrad}$. These conditions provide a nominal $0.07 \mathrm{~nm}$ beam, and were used for all images (Blom et al., 2006).

\section{RESULTS \\ Heater Performance}

The primary effect on the sample image of even very large temperature excursions is simply a change in focus (i.e., specimen height) because of expansion of the membrane during heating. Imaging at full resolution with no additional focus drift can commence immediately after Z-height adjustment, with allowance for normal stabilization of the stage itself $(\sim 30 \mathrm{~s})$, following a heating or cooling event. A high-angle annular dark-field (HA-ADF) image of a nanoparticle dispersion (Fig. 4), acquired with $64 \mathrm{~ms}$ line rate while the device was cycled periodically from $700^{\circ} \mathrm{C}$ to $\mathrm{RT}$, dramatically illustrates the cycling ability of the MEMS chip. The image was started in focus at $700^{\circ} \mathrm{C}$, and then the power was abruptly turned off for a short period and subsequently restored to the original setting, and so on. The total $\mathrm{Z}$ displacement between power on and power off was measured to be 1.7 microns for this particular device, over the selected temperature range. Even with this large displacement from the original focus position, the image returned to essentially the

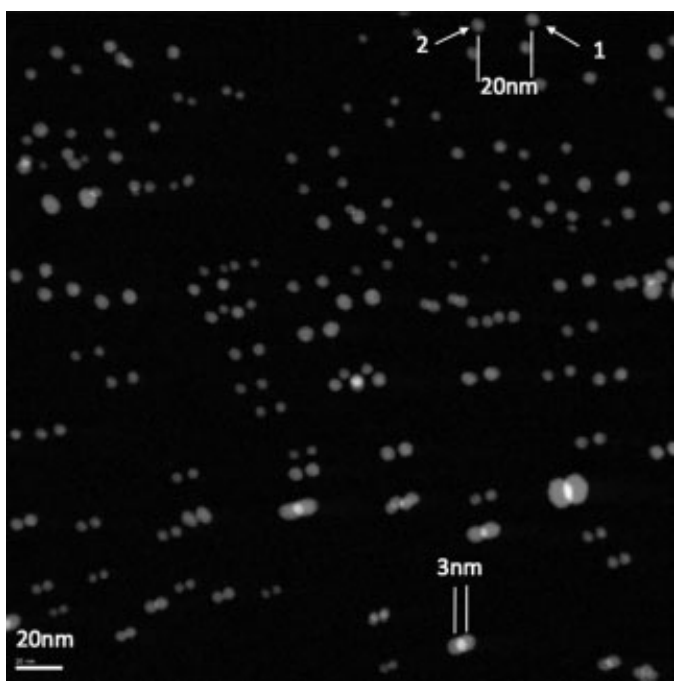

Fig. 5. Heater On-Off experiment, illustrating the small deflection in the X-Y plane after cycling from $700^{\circ} \mathrm{C}$ to RT. The overlapped image was started after a $15 \mathrm{~s}$ Off period, simultaneously with the start of the scan. An initial $20 \mathrm{~nm}$ displacement reduced to $3 \mathrm{~nm}$ in the time of the scan, about $17 \mathrm{~s}$.

same focus within one scan line. This test does not allow demonstrating the X-Y shift behavior of the image area however, an effect shown in Figure 5. This figure is an overlap of two images; one image was acquired at $700^{\circ} \mathrm{C}$ (scan time $\sim 20 \mathrm{~s}$ ), then the power was turned off for $\sim 10 \mathrm{~s}$ (but the $\mathrm{Z}$ position was held constant). The recording of the second image was started simultaneously with the power being restored to the heater. A final image was recorded immediately upon conclusion of the second image. The overlay of the first two images (Fig. 5) shows a displacement of $20 \mathrm{~nm}$ to the left in the $\mathrm{x}$ direction, and little displacement in the $y$ direction, at the beginning of the scan (note that the focus of the overlaid image is exactly the same as the first image, even though the membrane shifted by 1.7 microns in one direction when the current was turned off, and by 1.7 microns back when the current was restored). By the end of the scan, the residual displacement is only $3 \mathrm{~nm}$. A small "overshoot" of about $3 \mathrm{~nm}$ was noted with the second iteration, which was likely to simply be a measure of the inherent drift in the stage.

The very small X-Y shifts over a large temperature range show the outstanding general stability of the heater element. This is due primarily to the symmetry of the heater chip, and the fact that only the thin membrane heats up, whereas the much larger mass of the supporting Si chip remains cool. Figure 6 is another example of the ability to image at full instrument resolution with a sample at an elevated temperature. Recorded at a direct magnification of $15 \mathrm{Mx}$, single atoms of Pt are clearly imaged on a thin alumina area adjacent to a $\mathrm{Pt}$ nanoparticle, in a Pt/alumina catalyst material held at a nominal $700^{\circ} \mathrm{C}$.

\section{Example Application: Au-Pd Nanoparticles}

The unique behavior of the Protochips heater chip allows several operational modes during heater experiments. For example, many specimens show no signifi- 


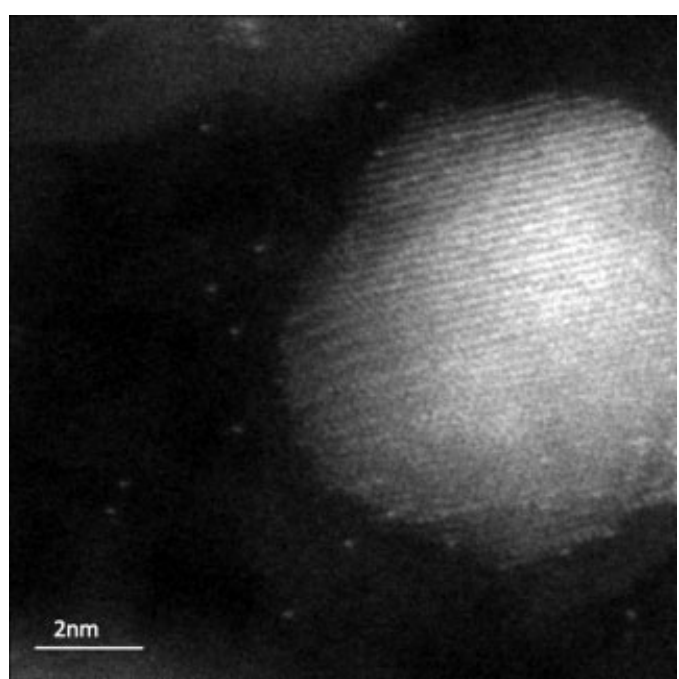

Fig. 6. HA-ADF Image of a Pt particle on alumina support material, at a nominal $700^{\circ} \mathrm{C}$, showing a number of single $\mathrm{Pt}$ atoms dispersed on the surface of the support.

cant morphological changes with temperatures in the range of $250-300^{\circ} \mathrm{C}$, where contamination effects are generally not observed. HA-ADF images can therefore be recorded with the sample at, say, $300^{\circ} \mathrm{C}$, the heater temperature increased to a desired value and the Zheight adjusted to recover focus, and the next images immediately recorded (usually within 30-60 s of the temperature increase). The beam can be blanked for periods of time while the sample is held at temperature, and a series of images can be taken at the chosen temperature at different times. Or, the specimen can be taken to a chosen temperature, held for a determined time, and then returned instantly to $300^{\circ} \mathrm{C}$ during the image recording process. This latter sequence has the advantage of minimizing the electron beam effects on the sample area being observed, because those effects may be more critical at the elevated temperature than at the lower observation temperature.

In our early experiments, we have been most interested in characterizing the behavior of the MEMS heaters with regard to the ability to record ultra-highresolution images in STEM ADF mode. For example, we observed the behavior of nanoparticles of AuPd that, in the as-prepared condition, show a core-shell structure, with a central core rich in $\mathrm{Pd}$, an inner shell rich in $\mathrm{Au}$, and an outer shell rich in Pd (Ferrer et al., 2007, 2008). These particles were dispersed in isopropyl alcohol, and a droplet deposited onto the holey carbon film over the heater surface. Several series of HA$\mathrm{ADF}$ and $\mathrm{BF}$ image pairs were recorded at magnifications from $500 \mathrm{kx}$ to $8 \mathrm{Mx}$, at temperatures gradually increased from $350^{\circ} \mathrm{C}$ to $900^{\circ} \mathrm{C}$, in steps of $50^{\circ} \mathrm{C}$. Figures $7 \mathrm{a}-7 \mathrm{c}$ show the behavior of a cluster of AuPd particles during this heating sequence. The core-shell structure is clear in Figure $7 \mathrm{a}$ at $350^{\circ} \mathrm{C}$, and has disappeared in Figure $7 \mathrm{~b}$ at a temperature of $550^{\circ} \mathrm{C}$, as the particles homogenize by diffusion. Particle A shows little change in size, whereas particle B shows a suggestion of growth; however these effects are small and may result simply from a small rearrangement in shape at this temperature. Two small clusters of AuPd atoms appear at the arrowed positions, probably as a result of migration of atomically dispersed species not seen at this magnification. Figure 7c shows the particle grouping at $700^{\circ} \mathrm{C}$. Remarkably, the center particle diminishes greatly in size, with the growth of a new grain on the adjacent surface of the larger particle. The two particles did not sinter together, even though they were apparently in contact at the higher temperature. New particle 1 grew also, but new particle 2 did not change appreciably after its initial formation at the lower temperature. The core-shell structure was not apparent in any particle, suggesting full alloying occurred after time at the higher temperature.

The set of BF images of Figures $7 d-7 f$, corresponding to the above HA-ADF set, provides additional information to the characterization of the behavior. Crystal lattice can be resolved in BF images at orientations somewhat farther away from the precise orientation required for $\mathrm{HA}-\mathrm{ADF}$ images. In Figure $7 \mathrm{~b}$ the beginning of growth of particle B is apparent, where the new material is not at the same crystal orientation as the original particle, in which the lattice is visible. At $700^{\circ} \mathrm{C}$ (Fig. 7c), particle B shows crystal lattice fringes, and is apparently two separate grains. Changes in lattice structure visible from one image to the next are largely the result of slight shifts in orientation of the particles because of the thermal effects. Figure 8 compares the HA-ADF images at the start (Fig. 8a) and after some time at $900^{\circ} \mathrm{C}$ (Fig. 8b). The new particle (arrow 1) grew continuously during the experiment, whereas the tiny new particle (arrow 2) did not increase in size from its original nucleation size during the entire experiment. The largest particle shows additional material of low contrast, suggesting that it might be composed primarily of $\mathrm{Pd}$ species. Original particle A shows only a tiny residual cluster. It was observed during the entire experiment to gradually diminish in size, with the growth of adjacent particle $\mathrm{B}$, but never to sinter with $\mathrm{B}$. The other two primary particles showed only a small diminishment in size over the course of the experiment.

Because a series of images was acquired at several magnifications for each temperature, it was useful to examine lower magnification images at the beginning and at the end of the heating experiment, to determine if there were noticeable electron beam effects on the area imaged at high magnification, versus areas that saw much lower electron beam exposures. Figures 9a and $9 \mathrm{~b}$ were recorded at $1 \mathrm{Mx}$ at the start of the experiment, and at the $700^{\circ}$ temperature, respectively. The white rectangles outline the areas exposed at the $5 \mathrm{Mx}$ magnification and higher. Careful inspection of both images shows anomalous changes in several other areas (circled), but in most instances particles with similar groupings as the imaged set did not show as dramatic changes. This suggests that the additional energy input of the electron beam may in fact have played a role in the behavior of the particles imaged in Figures 7 and 8 .

\section{DISCUSSION}

The intent of this report is to illustrate some of the unique capabilities of the MEMS-based heating devices. Most notable are the ultra-fast heating response, and the outstanding stability of the chip that allows 

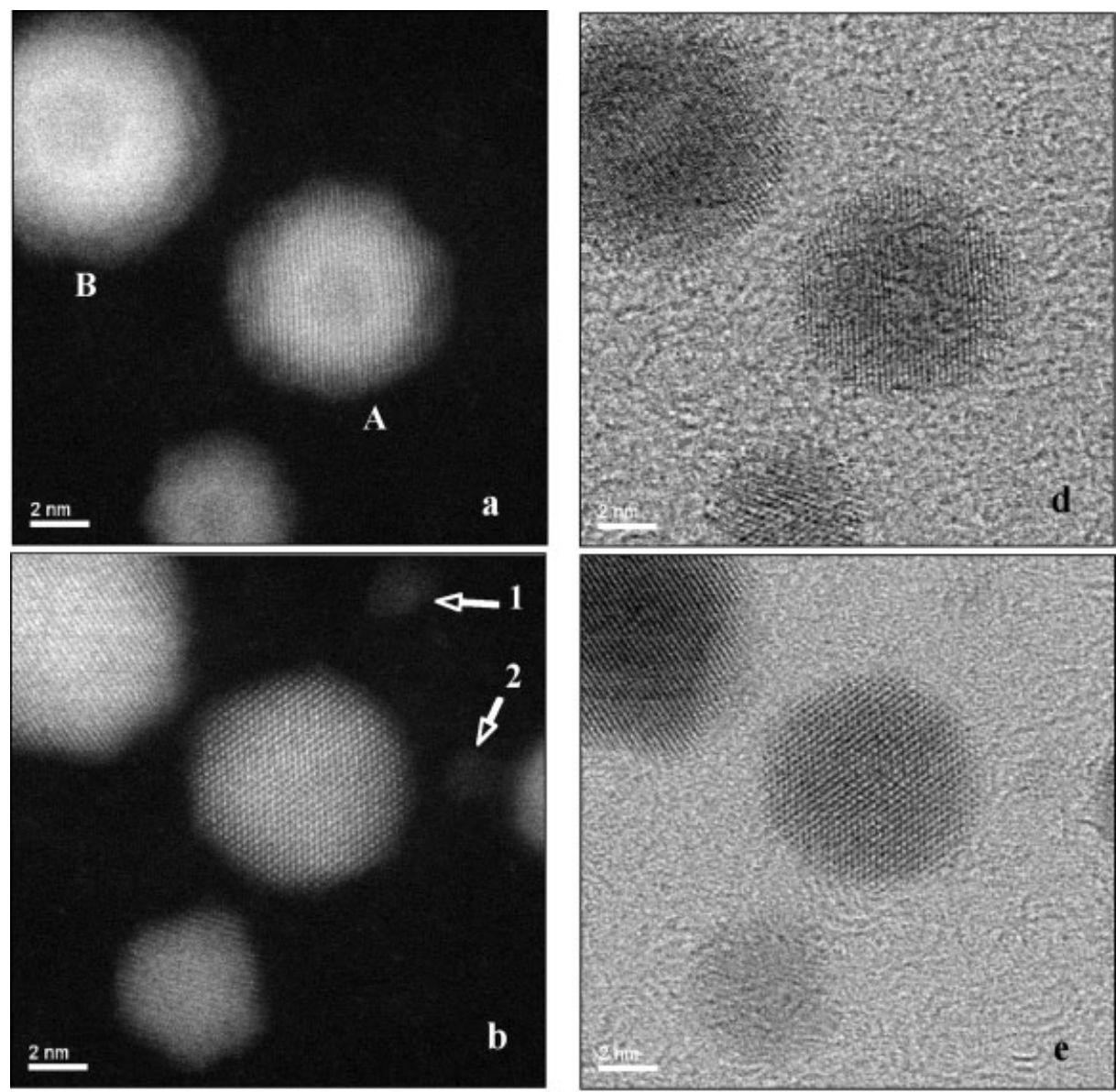

Fig. 7. Series of $\mathrm{HA}-\mathrm{ADF}$ and $\mathrm{BF}$ image pairs showing heating effects on three-layer $\mathrm{Au}-\mathrm{Pd}$ particles at $350^{\circ} \mathrm{C}(\mathbf{a}, \mathbf{d}), 550^{\circ} \mathrm{C}(\mathbf{b}, \mathbf{e})$, and $700^{\circ} \mathrm{C}$ $(\mathbf{c}, \mathbf{f})$. See text for details. Magnification marker denotes $2 \mathrm{~nm}$.
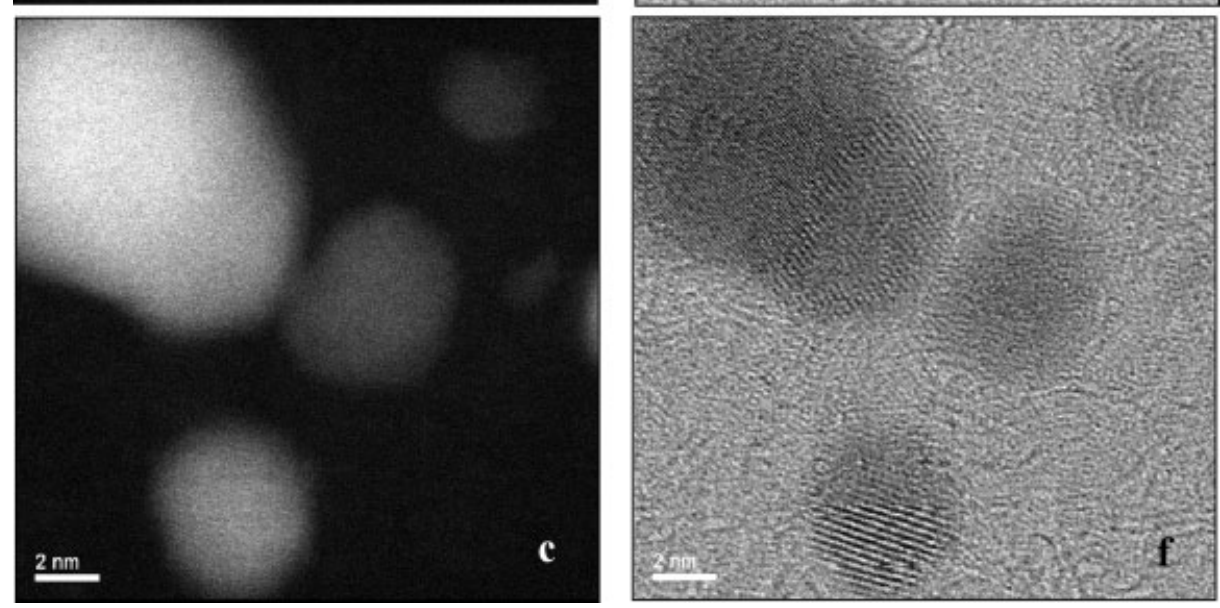

routine recording of scanning images that show singleatom resolution, within a very short time after large temperature excursions. The low mass of the Protochips membrane heater, even compared to, for example, the low mass coil heater of the Hitachi design [e.g., (Saka et al., 2008)], allows heating to temperatures in excess of $1000^{\circ} \mathrm{C}$ at a total heater power of $0.05-0.30$ W. This is a factor of 5 lower than the heating power of the Hitachi device, and orders of magnitude lower than the power expended in other bulk heaters that use indirect heating designs. The small heating area
$(0.5 \mathrm{~mm} \times 0.5 \mathrm{~mm})$ that is symmetrically supported by bulk silicon results in X-Y displacements in the few $\mathrm{nm}$ range, and a return to stability within a few seconds of a large temperature excursion. Our experience suggests that sample drift is controlled solely by the inherent drift of the stage, which is typically below $0.5 \mathrm{~nm} /$ min. For this reason, the recording of high resolution scanning images is possible, limited only by the stability of the sample itself under elevated temperature conditions. Finally, although we do not demonstrate the capability in this article, the Keithley power supply is 

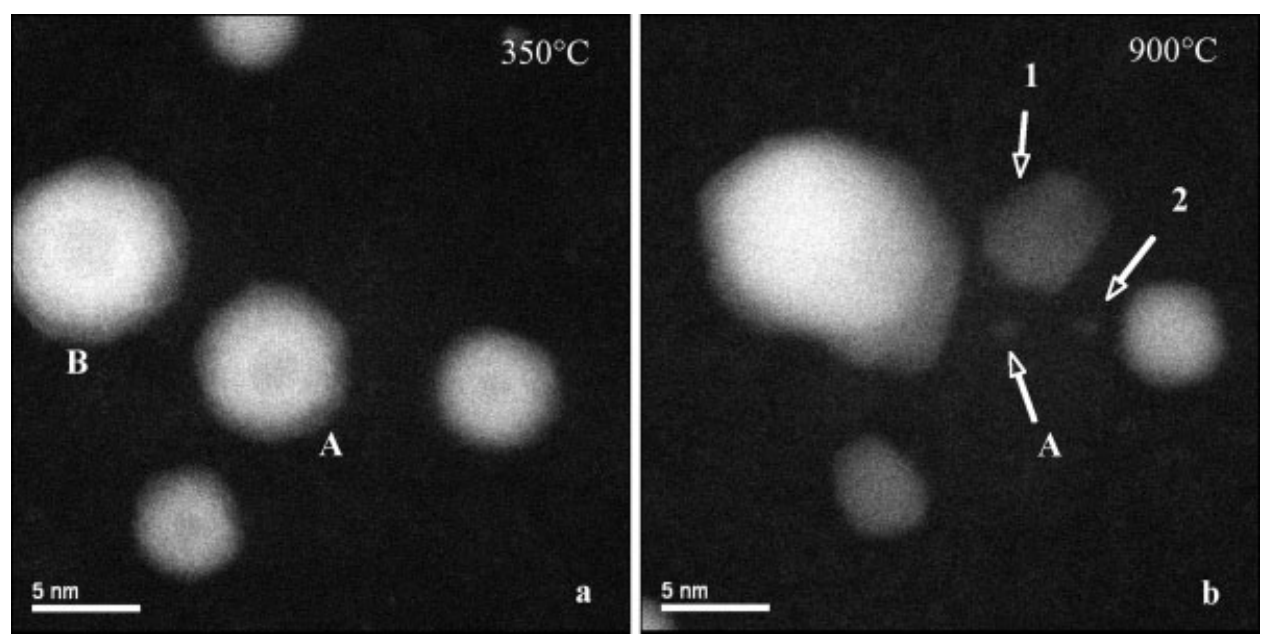

Fig. 8. Comparison of the AuPd particle cluster at the starting temperature of $350^{\circ} \mathrm{C}(\mathbf{a})$ and at the final condition of $900^{\circ} \mathrm{C}(\mathbf{b})$. Particle A has nearly disappeared, and particle B shows a final layer of material, presumably supplied by particle A.

Fig. 9. Overall images of the area of the sample from which the higher magnification images were obtained (white square inset). In comparing image (a) with image (b), it is evident that the area imaged in Figure 8 has undergone significant changes, relative to the generally apparent changes in surrounding clusters of particles. The smallest particles (arrowed) typically disappear. However, areas circled, which did not experience the same level of electron beam exposure, show changes in particle morphology similar to the original area. See text for details.
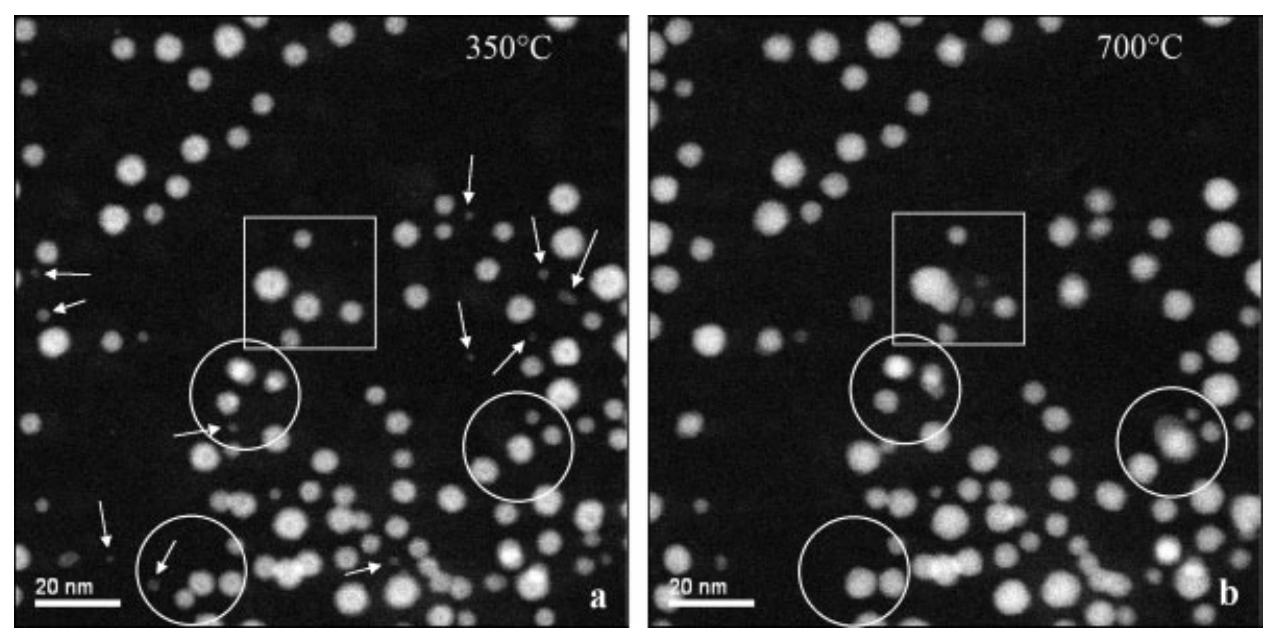

remotely programmable, and we are testing the beta version of software designed to run on our microscope's computer control system that permits the operator to set up programmed runs remote to the power supply. The ultimate result of this capability will permit total control of the JEOL 2200FS instrument during a heating experiment, even from a distant location, through our already demonstrated capability for remote instrument operation (Perkins et al., 2007).

Imaging in STEM mode in an aberration-corrected electron microscope at magnifications that give the highest resolutions requires significant beam exposures, so there is growing interest in, and examples of, the effects of the beam on the behavior of the structures being imaged (Batson, 2005, 2008). We have not yet attempted to quantify the relative effects of the electron beam in relation to the effects of higher temperatures on, say, the behavior of catalytic nanoclusters and particles, but the unique heating and cooling capabilities of the Protochips heater offers tantalizing possibilities to do so. In our application example, the clear homogenization of the 3-layer Au-Pd particles was an expected result, explained by a diffusion mechanism. To our knowledge, this is the first time that direct diffusive reconstruction of an alloy particle has been directly observed. The reasons for the unexpected failure of two primary particles to sinter, but instead to show growth of one particle at the expense of the other, are not immediately clear. One possibility is that particles acquire some charge during the observations, affecting the surface energy. The growth behavior is reminiscent of Ostwald ripening effects, although our system involves particle behavior on a uniform surface, whereas Ostwald ripening generally involves particle coarsening in solid or liquid solutions. The behavior of the particles in the example of Figure 8 was not uniformly consistent with Oswald ripening, however, as not all smaller particles diminished in size with respect to adjacent larger particles. We have established collaborations with a number of research groups having an interest in these issues, and the thrust of the work in the near future will be to understand these effects, both on nanoparticles and on highly dispersed species on both model and "real" supports. An extension of the basic heater device, also using the MEMS chips as the heating elements, to an environmental cell capability for gas reaction studies will be available in the near term, with results to be reported as soon as they are available. 


\section{CONCLUSIONS}

The present work has shown the ability of the unique MEMS-based heating devices fabricated by Protochips Co. to (a) allow ultra-fast heating and cooling responses from RT to greater than $1000^{\circ} \mathrm{C}$; (b) provide an inherently stable support that allows images to be recorded effectively at the highest resolution of an aberrationcorrected STEM instrument within seconds of a temperature excursion; and (c) provide a new capability for the conduct of in situ heating experiments not available with any current system designs.

\section{ACKNOWLEDGMENTS}

This research was performed at Oak Ridge National Laboratory (ORNL). The authors thank L.R. Walker, ORNL, for supplying the SEM image of Figure $1 \mathrm{~d}$, and T.A. Nolan, ORNL, for critical reading of the manuscript.

\section{REFERENCES}

Baker RTK. 1979. In situ electron microscopy studies of catalyst particle behavior. Catal Rev 19:161-209.

Batson PE. 2005. Atomic motion observed with the IBM Sub-Ång ström STEM. Microsc Microanal 11(Suppl 2):2124-2125.

Batson PE. 2008. Motion of gold atoms on carbon in the aberrationcorrected STEM. Microsc Microanal 14:89-97.

Blom DA, Allard LF, Mishina S, O’Keefe MA. 2006. Early results from an aberration-corrected JEOL 2200FS STEM/TEM at Oak Ridge National Laboratory. Microsc Microanal 12:483-491.

Boyes ED, Gai PL. 1997. Environmental high-resolution electron microscopy and applications to chemical science. Ultramicroscopy 67:219-232

Braski DN. 1970. High-vacuum evaporation stage for an electron microscope. J Vac Sci Technol 7:164-168.
Ferrer D, Torres-Castro A, Gao X, Sepulveda-Guzman S, Ortiz-Mendez U, Jose-Yacaman M. 2007. Three-layer core/shell structure in $\mathrm{Au}-\mathrm{Pd}$ bimetallic nanoparticles. Nano Lett 7:1701-1705.

Ferrer D, Blom DA, Allard LF, Mejia S, Perez-Tijerina E, Jose-Yacaman M. 2008. Atomic structure of three-layer Au/Pd nanoparticles revealed by aberration-corrected scanning transmission electron microscopy. J Mater Chem 8:2442-2446.

Gai PL. 1999. Environmental high resolution electron microscopy of gas-catalyst reactions. Top Catal 8:97-113.

Gai PL. 2002. Developments in in situ environmental cell high-resolution electron microscopy and applications to catalysis. Top Catal 21:161-173.

Heinemann K, Rao DB, Douglass DL. 1975. Oxide nucleation on thin films of copper during in situ oxidation in an electron microscope. Oxidation Met 9:379-400.

Kamino T, Yaguchi T, Konno M, Watabe A, Marukawa T, Mima T, Kuroda K, Saka H, Arai S, Makino H, Suzuki Y, Kishita K. 2005a. Development of a gas injection/specimen heating holder for use with transmission electron microscope. J Electron Microsc 54:497-503.

Kamino T, Yaguchi T, Sato T, Hashimoto T. 2005b. Development of a technique for high-resolution electron microscopic observation of nano-materials at elevated temperatures. J Electron Microsc 54:505-508.

Kamino T, Yaguchi T, Konno M, Watabe A, Nagakubo Y. 2006. Development of a specimen-heating holder with an evaporator and gas injector and its application to catalysis. J Electron Microsc 55:245-252.

Packan NH, Braski DN. 1970. Electron microscope in situ annealing study of voids induced by irradiation in aluminum. J Nucl Mater 34:307-314.

Perkins JM, Blom DA, McComb DW, Allard LF. 2007. Functional remote microscopy via the AtlanTICC Alliance. Microsc Microanal 13(Suppl 02):1431-1432.

Saka H, Kamino T, Arai S, Sasaki K. 2008. In situ heating transmission electron microscopy. MRS Bull 33:93-100.

Sharma R. 2001. Design and applications of environmental cell transmission electron microscope for in situ observations of gas-solid reactions. Microsc Microanal 7:494-506.

Sharma R, Weiss K. 1998. Development of a TEM to study in situ structural and chemical changes at an atomic level during gas-solid interactions at elevated temperatures. Microsc Res Tech 42:270280 . 